\title{
Lipase-Catalyzed Ring-Opening Polymerization of Lactones in Water
}

\author{
Shuhei Namekawa, Hiroshi Uyama, ${ }^{*}$ and Shiro Kobayashi ${ }^{*}, \dagger$ \\ Department of Materials Chemistry, Graduate School of Engineering, \\ Tohoku University, Sendai 980-77, Japan \\ * Department of Materials Chemistry, Graduate School of Engineering, \\ Kyoto University, Kyoto 606-01, Japan
}

(Received October 9, 1997)

KEY WORDS Enzymatic Polymerization/Ring-Opening Polymerization/Lipase / Lactone / Macrolide /

Recently, polymerizations catalyzed by enzymes ("enzymatic polymerizations") become known as new methodology of polymer syntheses. ${ }^{1-3}$ Until now, the in vitro syntheses of natural polysaccharides (cellulose, chitin, xylan, etc. $)^{4-6}$ via non-biosynthetic route as well as non-natural polymers such as aliphatic polyesters ${ }^{7-10}$ and polyaromatics ${ }^{1-13}$ have been achieved. As to the enzymatic synthesis of the polyesters, various monomer combinations have been extensively investigated.

We have systematically studied lipase-catalyzed ringopening polymerization and copolymerization of lactones of various ring-sizes: small-(4-membered), medium(6- and 7-membered), and macrocyclic lactones (12-, 13-, and 16-membered lactones) were subjected to be polymerized through lipase catalysis to give the corresponding polyesters. ${ }^{14-19}$ The macrocyclic lactones (macrolides) with smaller strain in ring, which thus show lower anionic polymerizability, were found to be polymerized much faster by lipase catalyst than $\varepsilon$-caprolactone $(\varepsilon-C L)$. This is probably due to a favored transition state of the macrolide to open the ring.

In most cases, lipase-catalyzed esterifications, transesterifications, and polymerizations are performed in non-polar organic solvents or bulk, since lipase acts as hydrolysis catalyst of ester moiety in the presence of water. $^{20,21}$ Very recently, we have found that dehydration polymerization of a dicarboxylic acid and a glycol proceeded in water by using lipase catalyst, ${ }^{22}$ which suggests the possibility of enzymatic synthesis of polyesters in an aqueous medium. This study deals with the lipase-catalyzed ring-opening polymerization of lactones in water (Scheme 1).

\section{RESULTS AND DISCUSSION}

At first, enzymatic ring-opening polymerization of 12dodecanolide (13-membered lactone, DDL) was per-

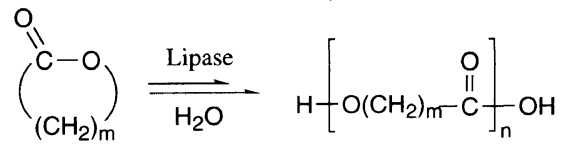

$$
\begin{aligned}
& \mathrm{m}=5: \varepsilon-\mathrm{CL} \quad \mathrm{m}=7: 8-\mathrm{OL} \quad \mathrm{m}=10: \mathrm{UDL} \\
& \mathrm{m}=11 \text { : DDL } \mathrm{m}=14 \text { : PDL }
\end{aligned}
$$

Scheme 1.

\footnotetext{
${ }^{\dagger}$ To whom correspondence should be addressed.
}

formed in the presence of lipase derived from Pseudomonas cepacia (lipase PC) under stirring at $60^{\circ} \mathrm{C}$ for $72 \mathrm{~h}$ (entry 6 in Table I). DDL is hardly soluble in water, then not mixed with water. By the addition of lipase PC, the heterogeneous mixture soon became a white emulsion, which was stable without stirring after the reaction. After lyophilization of the mixture, the polymer was extracted with chloroform and purified by reprecipitation (chloroform as good solvent and methanol as poor solvent) to give the polymer in $77 \%$ yield. The molecular weight was determined by size exclusion chromatography (SEC) as 1100 . In the polymerization without lipase PC (control experiment), the polymeric products were not formed (entry 9), indicating that the polymerization of DDL proceeded through the enzyme catalysis. The polymerization for longer time $(168 \mathrm{~h})$ resulted in the lower yield of the polymer, compared with that for $72 \mathrm{~h}$ (entry 7 ). This may be due to the occurrence of the polyester hydrolysis during the reaction.

Recently, various lipases of different origin are commercially available. In this study, lipases derived from Candida cylindracea (lipase CC), Pseudomonas aeruginosa (lipase PA), and Pseudomonas fluorescens (lipase PF) were used as catalyst for the polymerization of DDL in water besides lipase PC. These lipases were reported to be active as catalyst for the polymerization of DDL in bulk. ${ }^{17}$ A stable emulsion was formed during the polymerization

\begin{tabular}{|c|c|c|c|c|c|c|}
\hline Entry & Monomer & Enzyme & $\frac{\text { Time }}{\mathrm{h}}$ & $\frac{\text { Yield }^{\mathrm{b}}}{\%}$ & $M_{n}^{\mathrm{c}}$ & $M_{w} / M_{n}^{\mathrm{c}}$ \\
\hline 1 & $\varepsilon-\mathrm{CL}$ & Lipase PC & 72 & 0 & & \\
\hline 2 & 8-OL & Lipase PC & 72 & 0 & & \\
\hline 3 & UDL & Lipase PC & 72 & 79 & 1300 & 2.1 \\
\hline 4 & DDL & Lipase CC & 72 & 10 & 700 & 1.4 \\
\hline 5 & DDL & Lipase PA & 72 & 32 & 1100 & 1.9 \\
\hline 6 & DDL & Lipase PC & 72 & 77 & $\begin{array}{l}1100 \\
2100^{\mathrm{d}}\end{array}$ & 2.0 \\
\hline 7 & DDL & Lipase PC & 168 & 56 & 1200 & 2.2 \\
\hline $\begin{array}{l}8 \\
9\end{array}$ & $\begin{array}{l}\text { DDL } \\
\text { DDL }\end{array}$ & Lipase PF & $\begin{array}{l}72 \\
72\end{array}$ & $\begin{array}{r}89 \\
0\end{array}$ & 1300 & 2.1 \\
\hline 10 & PDL & Lipase PC & 72 & 79 & 500 & 1.2 \\
\hline 11 & HDDA & Lipase PC & 72 & 77 & 400 & 2.0 \\
\hline
\end{tabular}

Table I. I. Enzymatic polymerization of lactones in water ${ }^{\text {a }}$

a Polymerization of lactone $(2 \mathrm{mmol})$ using lipase catalyst $(100 \mathrm{mg})$ in water $(10 \mathrm{~mL})$ at $60^{\circ} \mathrm{C}$. ${ }^{\mathrm{b}}$ Methanol-insoluble part. ${ }^{\mathrm{c}}$ Determined by SEC using chloroform eluent. ${ }^{\mathrm{d}}$ Determined by ${ }^{1} \mathrm{H}$ NMR. ${ }^{\mathrm{e}}$ Without enzyme. 
from all the enzymes. Among them, lipases PC and PF afforded the polymer in high yields (entries 6 and 8). The polymer yield by using lipase PA was lower than that by lipase PC or PF (entry 5). Lipase CC showed less catalytic activity for the present polymerization: the yield and molecular weight of the polymer were lower than those by other lipases (entry 4). These data indicate that the polymerization behavior depended on the lipase origin.

Next, the polymerization of other lactones of different ring-size was investigated by using lipase PC as catalyst. The lactone monomers used in this study were already found to be polymerized through lipase catalysis in bulk or organic solvents. In using $\varepsilon$-CL or 8-octanolide (9-membered lactone, 8-OL), the emulsion was not formed: the reaction mixture was slightly suspended during the polymerization, however, the monomer liquid and the aqueous phase were separated on standing after the polymerization. There were no polymeric products in the reaction mixture from these monomers (entries 1 and 2). On the other hand, 11-undecanolide (12-membered lactone, UDL) was polymerized in the aqueous medium and the polymerization result was comparable with that of DDL (entry 3). The polymerization of 15pentadecanolide (16-membered lactone, PDL) provided the stable emulsion and the yield of the methanolinsoluble part was relatively high, however, the molecular weight of the product was quite low $\left(M_{n}=500\right)$. All these data indicate that a lactone monomer with appropriate hydrophobicity was favored for the lipasecatalyzed polymerization in the aqueous medium.

We already reported that the enzymatically synthesized polylesters from lactones in bulk had a hydroxy group at one end of the polymer and a carboxylic acid at the other terminal. ${ }^{14,16,17}$ The structure of present polymers was confirmed by ${ }^{1} \mathrm{H}$ NMR spectroscopy. In the spectrum of poly(DDL) obtained by using lipase PC (entry 6), there were characteristic two triplet peaks at $\delta 3.7$ due to the $\alpha$-methylene protons of the terminal hydroxy group and at $\delta 2.4$ ascribed to the $\alpha$-methylene protons of the terminal carboxylic acid group, besides main peaks of poly(DDL): a triplet peak at $\delta 4.1$ due to $\mathrm{C}(=\mathrm{O}) \mathrm{OCH}_{2} \mathrm{C}$, a triplet peak at $\delta 2.3$ to $\mathrm{CCH}_{2} \mathrm{C}(=\mathrm{O}) \mathrm{O}$, a multiplet peak at $\delta 1.6$ due to $\mathrm{C}(=\mathrm{O}) \mathrm{OCH}_{2} \mathrm{CH}_{2} \mathrm{C}$ and $\mathrm{CCH}_{2} \mathrm{CH}_{2} \mathrm{C}(=\mathrm{O}) \mathrm{O}$, and a broad peak centered at $\delta 1.3$ to the other alkylene protons. These data indicate that the polymer from DDL in water had the same structure as that obtained in bulk. The molecular weight determined from the ratio of integrated areas of the peaks at $\delta 4.1$ and 3.7 was 2100 , larger than that determined by SEC. The smaller estimation of the polymer molecular weight by SEC may be due to the calibration by using polystyrene standards.

There is a possibility that in the present polymerization, the polyester is formed by the hydrolysis of the lactone to give the oxyacid, followed by its polycondensation, since there are much amount of water in the reaction system. Then, the polymerization of 12 -hydroxydodecanoic acid (HDDA), the oxyacid from DDL and water, was performed by using lipase PC in water (entry 11). The polymerization result using HDDA was different from that of DDL: the molecular weight of poly(HDDA) was much lower than that from DDL under the similar reaction conditions. From these data, the lipase-catalyzed polymerization of the lactone in water might proceed involving the ring-opening of the lactone by the nucleophilic attack of the serine residue of lipase (the active site of the enzyme), similarly as the polymerization in organic solvents, ${ }^{16,23}$ not via the hydrolysis of the lactone and the subsequent condensation of the resulting oxyacid.

In conclusion, the lipase-catalyzed polymerization of lactones proceeded in water to give the corresponding polyesters. The lipase origin as well as the ring size of the lactone affected the polymerization behaviors. The present study suggests that the enzymatic polymerization via the transesterification proceeds in an aqueous medium. It is to be noted that the emulsion formation is very much concerned with the occurrence of the polymerization in water. Further studies on the enzymatic synthesis of polyesters from other monomer combinations in the aqueous medium are now under way in our laboratory.

\section{EXPERIMENTAL}

\section{Materials}

$\varepsilon$-CL, UDL, DDL, and PDL were commercially available reagents and stored over freshly activated type 4 molecular sieves. 8-OL was synthesized according by the reaction of cyclooctanone with $m$-chloroperbenzoic acid in dichloromethane. ${ }^{24}$ Lipase PA was a gift from Nagase Seikagaku Co. Lipases PC and PF were donated by Amano Pharmaceutical Co. Lipase CC was purchased from Biocatalysts. Lipases and HDDA were used without further purification.

\section{Enzymatic Polymerization in Water}

A typical run was as follows (entry 6 in Table I). $0.40 \mathrm{~g}$ $(2.0 \mathrm{mmol})$ of DDL, $0.10 \mathrm{~g}$ of lipase PC, and $10 \mathrm{~mL}$ of water were placed in a dried tube and sealed. The tube was kept under stirring at $60^{\circ} \mathrm{C}$ for $72 \mathrm{~h}$. The reaction mixture was lyophilized and the residue was extracted with chloroform. The part of the organic solution was separated by filtration, followed by evaporation under reduced pressure. The residue was dissolved a small amount of chloroform and the solution was poured into a large amount of methanol to precipitate the polymeric materials. The polymer was collected by filtration and dried in vacuo to give $0.30 \mathrm{~g}$ of the polymer ( $77 \%$ yield).

\section{Measurements}

SEC analysis was carried out using a Tosoh SC8010 apparatus with a refractive index (RI) detector under the following conditions: TSKgel $\mathrm{G} 3000 \mathrm{H}_{\mathrm{HR}}$ column and chloroform eluent at a flow rate of $1.0 \mathrm{~mL} \mathrm{~min}^{-1}$. The calibration curves for SEC analysis were obtained using polystyrene standards. ${ }^{1} \mathrm{H}$ NMR spectra were recorded on a $400 \mathrm{MHz}$ Bruker DPX-400 spectrometer.

Acknowledgments. This work was supported by a Grant-in-Aid for Specially Promoted Research (No. 08102002) from the Ministry of Education, Science, and Culture of Japan. We acknowledge the gift of lipases from Amano Pharmaceutical Co. and Nagase Seikagaku Co. 


\section{REFERENCES}

1. S. Kobayashi, S. Shoda, H. Uyama, in "Catalysis in Precision Polymerization," S. Kobayashi, Ed., John Wiley \& Sons, Chichester, 1997, Chapter 8.

2. S. Kobayashi, S. Shoda, and H. Uyama, Adv. Polym. Sci., 121, 1 (1995).

3. H. Ritter, Trends Polym. Sci., 1, 171 (1993).

4. S. Kobayashi, K. Kashiwa, T. Kawasaki, and S. Shoda, J. Am. Chem. Soc., 113, 3079 (1991).

5. S. Kobayashi, T. Kiyosada, and S. Shoda, J. Am. Chem. Soc., 118, 13113 (1996).

6. S. Kobayashi, X. Wen, and S. Shoda, Macromolecules, 29, 2968 (1996).

7. D. Knani, A. L. Gutman, and D. H. Kohn, J. Polym. Sci., Polym. Chem. Ed., 31, 1221 (1993).

8. H. Uyama and S. Kobayashi, Chem. Lett., 1687 (1994).

9. R. T. MacDonald, S. K. Pulapura, Y. Y. Svirkin, R. A. Gross, D. L. Kaplan, J. A. Akkara, G. Swift, and S. Wolk, Macromolecules, 28, 73 (1995).

10. G. A. R. Nobes, R. J. Kazlauskas, and R. H. Marchessault, Macromolecules, 29, 4829 (1996).

11. S. Kobayashi, I. Kaneko, and H. Uyama, Chem. Lett., 393 (1992).
12. H. Uyama, H. Kurioka, I. Kaneko, and S. Kobayashi, Chem. Lett., 423 (1994).

13. R. Ikeda, H. Uyama, and S. Kobayashi, Macromolecules, 29. 3053 (1996).

14. H. Uyama and S. Kobayashi, Chem. Lett., 1149 (1993).

15. H. Uyama, K. Takeya, and S. Kobayashi, Proc. Jpn. Acad., 69B, 203 (1993).

16. H. Uyama, K. Takeya, and S. Kobayashi, Bull. Chem. Soc. Jpn., 68, 56 (1995)

17. H. Uyama, K. Takeya, N. Hoshi, and S. Kobayashi, Macromolecules, 28, 7046 (1995).

18. H. Uyama, H. Kikuchi, K. Takeya, and S. Kobayashi, Acta Polymerica, 47, 357 (1996).

19. S. Namekawa, H. Uyama, and S. Kobayashi, Polym. J., 28, 730 (1996).

20. J. B. Jones, Tetrahedron, 42, 3351 (1986).

21. E. Santaniello, P. Ferraboschi, P. Grisenti, and A. Manzocchi, Chem. Rev., 92, 1071 (1992).

22. S. Kobayashi, H. Uyama, S. Suda, and S. Namekawa, Chem. Lett., 107 (1997).

23. H. Uyama, S. Namekawa, and S. Kobayashi, Polym. J., 29, 299 (1997).

24. E. Fouque and G. Rousseau, Synthesis, 661 (1989). 